\title{
Protective effect of the herbal medicine Gan-fu-kang against carbon tetrachloride-induced liver fibrosis in rats
}

\author{
CAIHUA ZHANG $^{1 *}$, YANFU WANG $^{2 *}$, HONG CHEN $^{1}$, GUANG YANG $^{1}$, SHAOPENG WANG $^{2}$, \\ MIAONA JIANG ${ }^{1}$, LI CONG $^{1}$, LIJUN YUAN ${ }^{1}$, HANSHU LI $^{1}$ and YUJIE JIA ${ }^{1}$ \\ ${ }^{1}$ Department of Pathophysiology, Dalian Medical University, Dalian, Liaoning 116044; \\ ${ }^{2}$ The First Affiliated Hospital, Dalian Medical University, Dalian, Liaoning 116011, P.R. China
}

Received February 3, 2013; Accepted July 8, 2013

DOI: $10.3892 / \mathrm{mmr} .2013 .1587$

\begin{abstract}
The aim of the present study was to investigate the effect of a herbal medicine formula, Gan-fu-kang (GFK), on the treatment of liver fibrosis in rats and the mechanisms via which it exerts its effect. Liver fibrosis was induced in rats by subcutaneous injection of carbon tetrachloride $\left(\mathrm{CCl}_{4}\right)$ at $0.5 \mathrm{mg} / \mathrm{kg}$ body weight, twice a week for 8 weeks. The rats were randomly selected to receive saline or GFK at 31.25, 312.5 or $3,125 \mathrm{mg} / \mathrm{kg}$ body weight/day between weeks 9 and 20. An additional group of rats without $\mathrm{CCl}_{4}$ injection was used as the baseline. In the liver fibrosis model rats, an increase in plasma liver enzymes, fibrotic markers in serum and liver fibrosis, production of $\alpha$-smooth muscle actin, matrix metalloproteinase-2 and tissue inhibitor of metalloproteinase-1, synthesis of collagen and activation of the Wnt/ $\beta$-catenin signaling pathway were observed. GFK administration was found to significantly reduce these changes. Results of this study demonstrate that GFK has a protective and therapeutic effect on liver fibrosis induced by $\mathrm{CCl}_{4}$, which may be associated with its inhibitory activity on HSC proliferation and collagen synthesis, effectively downregulating Wnt/ $\beta$-catenin signaling.
\end{abstract}

\section{Introduction}

Liver fibrosis is a wound-healing process involving the activation of hepatic stellate cells (HSCs) and an increased deposition of extracellular matrix (ECM) components, including type I/III collagen, metalloproteinases (MMPs) and tissue inhibitors of metalloproteinases (TIMPs) $(1,2)$. HSCs play pivotal roles

Correspondence to: Professor Yujie Jia, Department of Pathophysiology, Dalian Medical University, South Road West Section 9, Dalian, Liaoning 116044, P.R. China

E-mail: pathophy@hotmail.com

${ }^{*}$ Contributed equally

Key words: liver fibrosis, Gan-fu-kang, Wnt, $\beta$-catenin, carbon tetrachloride in fibrogenesis in the liver $(3,4)$. Following injury, HSCs are activated and undergo complex transdifferentiation, leading to increased proliferation, migration and contraction and a shift towards synthesis and deposition of ECM materials, contributing to scar formation and eventually cirrhosis (5-7). A characteristic feature of activated HSCs is the activation of several cytokine mediators, including transforming growth factor- $\beta$ (TGF- $\beta$ ), platelet derived growth factor (PDGF) and angiotensin (8-10). Therefore, investigation of signaling pathways and identification of the potential therapeutic targets is extremely important.

Previous studies have demonstrated the ability of natural drugs to prevent the development of liver fibrosis $(11,12)$. Gan-fu-kang (GFK) is a traditional Chinese prescription herb complex that contains Salvia miltiorrhiza (Labiatae), milkvetch root (Leguminosae) and Angelica (Umbelliferae). Salvia miltiorrhiza plays an integral role in liver fibrosis by activating the circulation to remove blood stasis. In traditional Chinese medicine, milkvetch root is considered to supplement qi and provide body fluids, while Angelica replenishes blood. GFK is commonly used to treat human liver fibrosis induced by alcohol abuse and hepatitis, and has been demonstrated to induce protective and therapeutic effects to reverse liver fibrosis $(13,14)$.

The Wnt genes comprise a highly conserved family of secreted, hydrophobic glycoproteins that play a crucial role in regulating embryonic development, cellular differentiation and proliferation and polarity (15-17). Abnormal regulation of Wnt/ $\beta$-catenin signaling has been implicated in tumorigenesis and in the pathogenesis of a number of human diseases of diverse tissues (18-20). Once activated, it may activate downstream target genes, including c-jun, cyclinD1 and PPAR- $\gamma$, which in turn may promote the deposition of ECM and proliferation of HSC (21-23).

It has previously been reported that Wnt signaling may serve as the common downstream mediator of fibrogenic effects rendered by TGF- $\beta$, PDGF and other factors (24). Previous observations have indicated that GFK inhibits TGF- $\beta$ and MAPK/AP-1 pathways, thus providing a hepatoprotective effect $(13,14,25)$. Therefore, it was hypothesized that GFK exerts an antifibrotic effect by mediating the Wnt/ $\beta$-catenin signaling pathway. The present study aimed to investigate 
the effects of GFK treatment on the Wnt/ $\beta$-catenin signaling pathway.

\section{Materials and methods}

Herbal medicine. GFK is a traditional Chinese herbal formula containing Salvia miltiorrhiza, milkvetch root and Angelica. The crude drug was purchased from Dalian Medical University (Dalian, China) and extracted by the Department of Pathophysiology. The herbal decoction was stored at $-20^{\circ} \mathrm{C}$.

Animals. Adult Sprague-Dawley (SD) rats (1:1, male:female; 180-200 g) were purchased from the Experimental Animal Center of Dalian Medical University, [confirmation no., SCXK (Liao) 2004-0017]. All rats were fed with a standard pellet diet and tap water was available ad libitum during the experimental trial. The animals were maintained in an air-conditioned room at $20^{\circ} \mathrm{C}$ under a 12 -h light/dark cycle. All experiments were in strict accordance with the principle and guidelines of the National Institutes of Health Guide for the Care and Use of Laboratory Animals (26). The study was approved by the Ethics Committee of Dalian Medical University, Dalian, Liaoning, China

Animal model and drug treatment. Following a one-week acclimation period, rats were randomly divided into 5 groups: control $(n=12)$, carbon tetrachloride $4\left(\mathrm{CCl}_{4}\right)$ model $(\mathrm{n}=8)$ and three GFK groups $(n=11)$. Each group, with the exception of control, received $\mathrm{CCl}_{4}$ subcutaneously $(0.5 \mathrm{mg} / \mathrm{kg}$ in a vehicle of olive oil, twice/week) for 8 weeks. Following $\mathrm{CCl}_{4}$ treatment, rats randomly received GFK per os $(31.25,312.5$ and $3,125 \mathrm{mg} / \mathrm{kg} / \mathrm{day}$ ) or vehicle between weeks 9 and 20 . The control group received saline between weeks 1 and 20. All rats were sacrificed at the end of week 20 . Blood and liver samples were obtained for further examination.

Plasma assay for liver enzymes and fibrotic markers in serum. Plasma alanine aminotransferase (ALT) and aspartate aminotransferase (AST) were measured using commercial test reagents (Nanjing Jiancheng Bio, Nanjing, China). The concentrations of serum hyaluronic acid (HA), laminin (LN), procollagen type III (PCIII) and collagen type IV (CIV) were measured by radioimmunoassay kits provided by the General Hospital of People's Liberation Army (Beijing, China). The tests were performed according to the manufacturer's instructions (Purevalley Biotech, Beijing, China).

Histopathological evaluation. Tissue samples were fixed in $10 \%$ formalin, embedded in paraffin and processed by routine histological procedures. Following this, $4-5-\mu \mathrm{m}$-thick sections were stained with hematoxylin and eosin (H\&E) and picrosirius red staining. Sections were observed by light and polarizing microscopy, respectively. Fibrosis of H\&E staining was graded as described previously (27): 0, normal liver without hyperplasia of collagenous fibers; I, slight extension of collagenous fibers from portal area or central veins; II, marked extension of collagenous fibers, without connecting each other and encysting the whole hepatic lobules; III, marked extension of collagenous fibers, connecting each other and encysting the whole hepatic lobules; IV, hepatic lobules are encysted and separated by collagenous fibers. The normal structure of hepatic lobules is destroyed. The pseudolobules are formed and it is dominated by large square pseudolobuli; V, structure of hepatic lobules is fully destroyed and large square and small round pseudolobules occupy $50 \%$; VI, small round hepatic lobuli occupy almost the whole liver and the hyperplatic thick collagenous fibers are visible. All histological analysis was assigned by independent certified pathologists in a blind manner. Each sample was observed at magnifications of x400 and x200 and at least 10 fields of view were scored per liver slice to obtain the mean value.

Immunohistochemistry. Liver tissue sections were deparaffinized and hydrated in a graded alcohol series and washed in water. Antigens were retrieved in a pressure cooker in citrate buffer $(\mathrm{pH} 6.0)$ for $5 \mathrm{~min}$ at $1.0 \mathrm{kPa}$ and non-specific binding was blocked in 5\% BSA. Sections were sequentially incubated with one of the following primary antibodies overnight at $4^{\circ} \mathrm{C}$ : rat polyclonal anti-Tcf-4 (1:150), anti- $\alpha$-smooth muscle actin ( $\alpha$-SMA; 1:200; both BIOS, Beijing Biosynthesis Biotechnology Co. Ltd., Beijing, China)and anti- $\beta$-catenin (1:150; Santa Cruz Biotechnology, Inc., Santa Cruz, CA, USA). The Vectastain ABC kit was used to obtain the final stain and diaminobenzidine (DAB) was used as the chromogen. The slides were counterstained with hematoxylin. Negative controls were obtained by omitting the primary antibody. A minimum of five random fields per liver section was detected at magnification $\mathrm{x} 400$ and the semi-quantitative evaluations were assigned by the Image-pro-plus (Media Cybernetics Inc., Rockville, MD, USA).

Western blotting. Total and nuclear proteins were prepared according to standard instructions (28) and the concentration was estimated by a Bradford assay with BSA as standard. The primary antibodies, $\beta$-catenin $(1: 200), \beta$-actin $(1: 1,000)$ and Histone H1 (1:200; all Santa Cruz Biotechnology, Inc.), $\alpha$-SMA (1:400), TIMP-1 (1:300) and collagen I (1:200; all BIOS) were used. Equal amounts of protein (50 $\mu \mathrm{g} /$ lane) were separated by electrophoresis on a $10-12 \%$ SDS-polyacrylamide gel, transferred to polyvinylidene difluoride membranes (Millipore, Billerica, MA, USA) and blocked with $5 \%$ skimmed milk. The first antibodies were incubated overnight at $4^{\circ} \mathrm{C}$ and then appropriate secondary antibodies were added. Proteins were visualized by enhanced chemiluminescence detection (Santa Cruz Biotechnology, Inc.) as reported. Densitometric scanning was performed using the UVP Bioimaging Systems with Labwork 4.6 (UVP, LLC, Upland, CA, USA) to determine the band intensities. All experiments were repeated five times.

Reverse transcription-polymerase chain reaction ( $R T-P C R)$. Total RNA was extracted from rat liver samples using TRIzol reagent according to the manufacturer's instructions (Invitrogen Life Technologies, Carlsbad, CA, USA). cDNA templates were prepared using oligo(dT) random primers, and Quant reverse transcriptase and the Taq DNA polymerase kit were used for PCR (Tiangen Biotech, Beijing, China) with $\beta$-actin as a control. Primer set sequences are presented in Table I. To evaluate the amplification, electrophoresis of PCR products was performed using $2 \%$ agarose gels containing 
Table I. Primer sequences and amplicon sizes.

\begin{tabular}{|c|c|c|}
\hline Gene & Sequence $\left(5^{\prime}-3^{\prime}\right)$ & Amplicon length, bp \\
\hline \multirow[t]{2}{*}{ Wnt1 } & Forward: GAAACCGCCGCTGGAACT & 326 \\
\hline & Reverse: CCCTGCCTCGTTATTGTGAAG & \\
\hline \multirow{2}{*}{ Wnt3a } & Forward: GCAGTTGCGAAGTGAAGACC & 173 \\
\hline & Reverse: TGTGGGCACCTTGAAGTATGT & \\
\hline \multirow[t]{2}{*}{ Wnt 10b } & Forward: TCTCCTGTTCTTGGCTTTGTT & 246 \\
\hline & Reverse: TCTAGTGCCGAGCAGTTCC & \\
\hline \multirow[t]{2}{*}{ Frizzled-1 } & Forward: AAGTTCTTCCTGTGCTCCATGT & 384 \\
\hline & Reverse: CTCCCCCAGAAAGTGATAGTTG & \\
\hline \multirow[t]{2}{*}{ Frizzled-2 } & Forward: CCTGGAGGTGCATCAATTCTAC & 447 \\
\hline & Reverse: CGCTCACCCAGAAACTTATAGC & \\
\hline \multirow[t]{2}{*}{ GSK-3 $\beta$} & Forward: TACCTTAACCTGGTGCTGGACT & 453 \\
\hline & Reverse: TGTTGGTGTTCCTAGGACCTTT & \\
\hline \multirow[t]{2}{*}{$\beta$-catenin } & Forward: GATTAACTATCAGGATGACGCG & 780 \\
\hline & Reverse: TCCATCCCTTCCTGCTTAGTC & \\
\hline \multirow[t]{2}{*}{ Tcf-4 } & Forward: GCACTTACCAGCTGACGTAGAC & 557 \\
\hline & Reverse: GGGCTAGCTCGTAGTACTTTGC & \\
\hline \multirow[t]{2}{*}{ PPAR- $\gamma$} & Forward: TGTGGACCTCTCTGTGATGG & 127 \\
\hline & Reverse: CATTGGGTCAGCTCTTGTGA & \\
\hline \multirow[t]{2}{*}{ Cyclin D1 } & Forward: TGTTCGTGGCCTCTAAGATG & 450 \\
\hline & Reverse: ACTCCAGAAGGGCTTCAATC & \\
\hline \multirow{2}{*}{$\alpha$-SMA } & Forward: TGTGCTGGACTCTGGAGATG & 291 \\
\hline & Reverse: GATCACCTGCCCATCAGG & \\
\hline \multirow[t]{2}{*}{ Collagen I } & Forward: TGCCGTGACCTCAAGATGTG & 461 \\
\hline & Reverse: CACAAGCGTGCT GTAGGTGA & \\
\hline \multirow[t]{2}{*}{ Collagen III } & Forward: AGATCATGTCTTGACTCAAGTC & 463 \\
\hline & Reverse: TTTACATTGCCATTGGCCTGA & \\
\hline \multirow[t]{2}{*}{ MMP-2 } & Forward: GTGGACAAACTGAGCGAA & 541 \\
\hline & Reverse: AGGTAGGGTACATCACAGAA & \\
\hline \multirow[t]{2}{*}{ TIMP-1 } & Forward: GCCATGGAGAGCCTCTGTGG & 356 \\
\hline & Reverse: GCAGGCAGGCAAAGTGATCG & \\
\hline \multirow[t]{2}{*}{$\beta$-actin } & Forward: GGTATGGGTCAGAAGGACTCC & 847 \\
\hline & Reverse: TGATCTTCATGGTGCTAGGAGCC & \\
\hline
\end{tabular}

MMP, matrix metalloproteinase; TIMP-1, tissue inhibitor of metalloproteinase-1; $\alpha$-SMA, $\alpha$-smooth muscle actin.

ethidium bromide and then quantified using the UVP Bioimaging Systems.

Statistical analysis. Statistical analysis was performed using SPSS 11.5 software (SPSS, Inc., Chicago, IL, USA). All numerical data represent at least three independent experiments and are expressed as the mean $\pm \mathrm{SD}$. Comparison between groups was performed using a two-tailed Student's t-test. Pearson was employed for correlation analysis of parameters. $\mathrm{P}<0.05$ was considered to indicate a statistically significant difference.

\section{Results}

Effects of GFK on plasma hepatic enzyme and fibrotic markers in serum. Plasma ALT and AST increased significantly in $\mathrm{CCl}_{4}$ rats compared with the controls $(\mathrm{P}<0.01)$. Administration of GFK $(3,125$ and $312.5 \mathrm{mg} / \mathrm{kg} /$ day) significantly decreased ALT and
AST levels ( $\mathrm{P}<0.01$; Fig. 1). Similarly, in the $\mathrm{CCl}_{4}$ group, serum markers of HA, LN, PCIII and CIV were increased $(\mathrm{P}<0.05)$ and GFK (312.5 and $3,125 \mathrm{mg} / \mathrm{kg} / \mathrm{day})$ treatment significantly blocked $\mathrm{CCl}_{4}$-induced elevation of these markers (Table II).

Histopathological changes. Liver histopathological examination of the control group revealed a normal lobular architecture with central veins and radiating hepatic cords (Fig. 2A and B). In the $\mathrm{CCl}_{4}$-treated group, marked changes were observed in liver morphology, including steatosis, ballooning, necrosis and inflammatory infiltration (Fig. 2C). Picrosirius red staining revealed severe collagen deposition (Fig. 2D). By contrast, GFK treatment significantly alleviated the degree of liver fibrosis and ductular proliferation (Fig. 2E-H). The antifibrotic effect was less marked in GFK $(31.25 \mathrm{mg} / \mathrm{kg} /$ day; Fig. 2I and $\mathrm{J}$ ). The average scores for the degree of liver damage are presented in Table III. 
Table II. Levels of HA, LN, PCIII and CIV.

\begin{tabular}{lccccc}
\hline Group & Dose $(\mathrm{mg} / \mathrm{kg})$ & HA & LN & PCIII & CIV \\
\hline Control & & $58.96 \pm 4.51$ & $10.36 \pm 2.56$ & $16.63 \pm 3.54$ & $77.83 \pm 11.44$ \\
Model & & $151.99 \pm 8.23^{\mathrm{a}}$ & $32.33 \pm 3.28^{\mathrm{a}}$ & $43.83 \pm 8.33^{\mathrm{a}}$ & $155.85 \pm 25.09^{\mathrm{a}}$ \\
GFK & 3125.00 & $84.23 \pm 4.91^{\mathrm{a}, \mathrm{b}}$ & $17.05 \pm 2.92^{\mathrm{a}, \mathrm{b}}$ & $26.41 \pm 3.21^{\mathrm{a}, \mathrm{b}}$ & $94.99 \pm 9.010^{\mathrm{a}, \mathrm{b}}$ \\
GFK & 312.50 & $60.01 \pm 5.78^{\mathrm{b}}$ & $11.18 \pm 2.15^{\mathrm{b}}$ & $17.13 \pm 4.06^{\mathrm{b}}$ & $78.21 \pm 6.820^{\mathrm{b}}$ \\
GFK & 31.25 & $88.71 \pm 4.47^{\mathrm{a}, \mathrm{b}}$ & $18.56 \pm 2.30^{\mathrm{a}, \mathrm{b}}$ & $25.27 \pm 5.15^{\mathrm{a}, \mathrm{b}}$ & $100.23 \pm 11.67^{\mathrm{a}, \mathrm{b}}$ \\
\hline
\end{tabular}

${ }^{\mathrm{a}} \mathrm{P}<0.05$, vs. control; ${ }^{\mathrm{b}} \mathrm{P}<0.05$, vs. CCl4 model. GFK, Gan-fu-kang; HA, hyaluranic acid; LN, lamin; PCIII, procollagen type III, CIV collagen type IV; $\mathrm{CCl}_{4}$, carbon tetrachloride 4 .

Table III. Effect of GFK on the pathological grading of liver fibrosis induced by CCl4.

\begin{tabular}{|c|c|c|c|c|c|c|c|c|c|c|}
\hline \multirow[b]{2}{*}{ Group } & \multirow{2}{*}{$\begin{array}{c}\text { Dose } \\
(\mathrm{mg} / \mathrm{kg})\end{array}$} & \multirow[b]{2}{*}{$\mathrm{n}$} & \multicolumn{7}{|c|}{ Degree of liver fibrosis } & \multirow[b]{2}{*}{ P-value } \\
\hline & & & 0 & I & II & III & IV & V & VI & \\
\hline Control & & 12 & 12 & 0 & 0 & 0 & 0 & 0 & 0 & \\
\hline Model & & 7 & 0 & 0 & 1 & 1 & 2 & 3 & 0 & a \\
\hline GFK & 3125.00 & 11 & 0 & 3 & 4 & 3 & 1 & 0 & 0 & $\mathrm{~b}$ \\
\hline GFK & 312.50 & 11 & 0 & 4 & 7 & 0 & 0 & 0 & 0 & $\mathrm{~b}$ \\
\hline GFK & 31.25 & 11 & 0 & 1 & 5 & 2 & 3 & 0 & 0 & $\mathrm{~b}$ \\
\hline
\end{tabular}

${ }^{\text {a }} \mathrm{P}<0.01$, vs. control; ${ }^{\text {}} \mathrm{P}<0.05$, vs. $\mathrm{CCl}_{4}$ model. GFK, Gan-fu-kang; $\mathrm{CCl}_{4}$, carbon tetrachloride 4 .

Table IV. Correlation analysis in the model and GFK $(312.5 \mathrm{mg} / \mathrm{kg})$ groups.

\begin{tabular}{|c|c|c|c|c|c|c|c|c|}
\hline & \multicolumn{2}{|c|}{$\alpha$-SMA } & \multicolumn{2}{|c|}{ TIMP-1 } & \multicolumn{2}{|c|}{ Collagen I } & \multicolumn{2}{|c|}{ Collagen III } \\
\hline & $\mathrm{r}$ & P-value & $\mathrm{r}$ & P-value & $\mathrm{r}$ & P-value & $\mathrm{r}$ & P-value \\
\hline Wnt3a & 0.958 & $<0.05$ & 0.889 & $<0.05$ & 0.980 & $<0.01$ & 0.993 & $<0.01$ \\
\hline Wnt10b & 0.993 & $<0.01$ & 0.896 & $<0.05$ & 0.976 & $<0.01$ & 0.962 & $<0.01$ \\
\hline$\beta$-catenin & 0.963 & $<0.05$ & 0.921 & $<0.01$ & 0.980 & $<0.01$ & 0.980 & $<0.01$ \\
\hline Tcf-4 & 0.880 & $<0.05$ & - & - & 0.815 & $<0.05$ & 0.892 & $<0.05$ \\
\hline
\end{tabular}

Values are presented as correlation coefficients (r) and significant levels (P). GFK, Gan-fu-kang; TIMP-1, tissue inhibitors of metalloproteinase 1 .

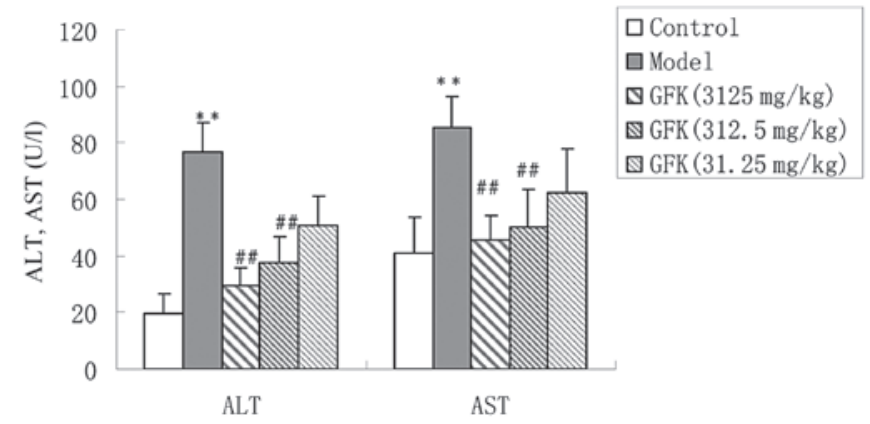

Figure 1. Serum levels of ALT and AST activities. Results are expressed as the mean $\pm \mathrm{SD} .{ }^{* *} \mathrm{P}<0.01$, vs control; ${ }^{\# \#} \mathrm{P}<0.01$, vs model. ALT, alanine aminotransferase; AST, aspartate aminotransferase.
Effect of GFK on $\alpha$-SMA, collagen I, collagen III, MMP-2 and TIMP-1. To identify HSCs in the liver, immunohistochemistry was used to detect the expression of $\alpha$-SMA, a marker of activated hepatic stellate cells. In the control group, $\alpha$-SMA was predominantly located in the blood vessel wall, while in the model group, markedly higher expression of $\alpha$-SMA was found in the portal area, fibrous septum and space of Disse $(\mathrm{P}<0.01) . \alpha$-SMA-positive cells were reduced markedly in rats receiving GFK treatment (Fig. 3).

RT-PCR results revealed that $\alpha$-SMA, collagen I, collagen III, MMP-2 and TIMP-1 mRNA levels increased significantly in $\mathrm{CCl}_{4}$-treated rats and was inhibited by GFK, with similar levels compared with control animals. Treatment 

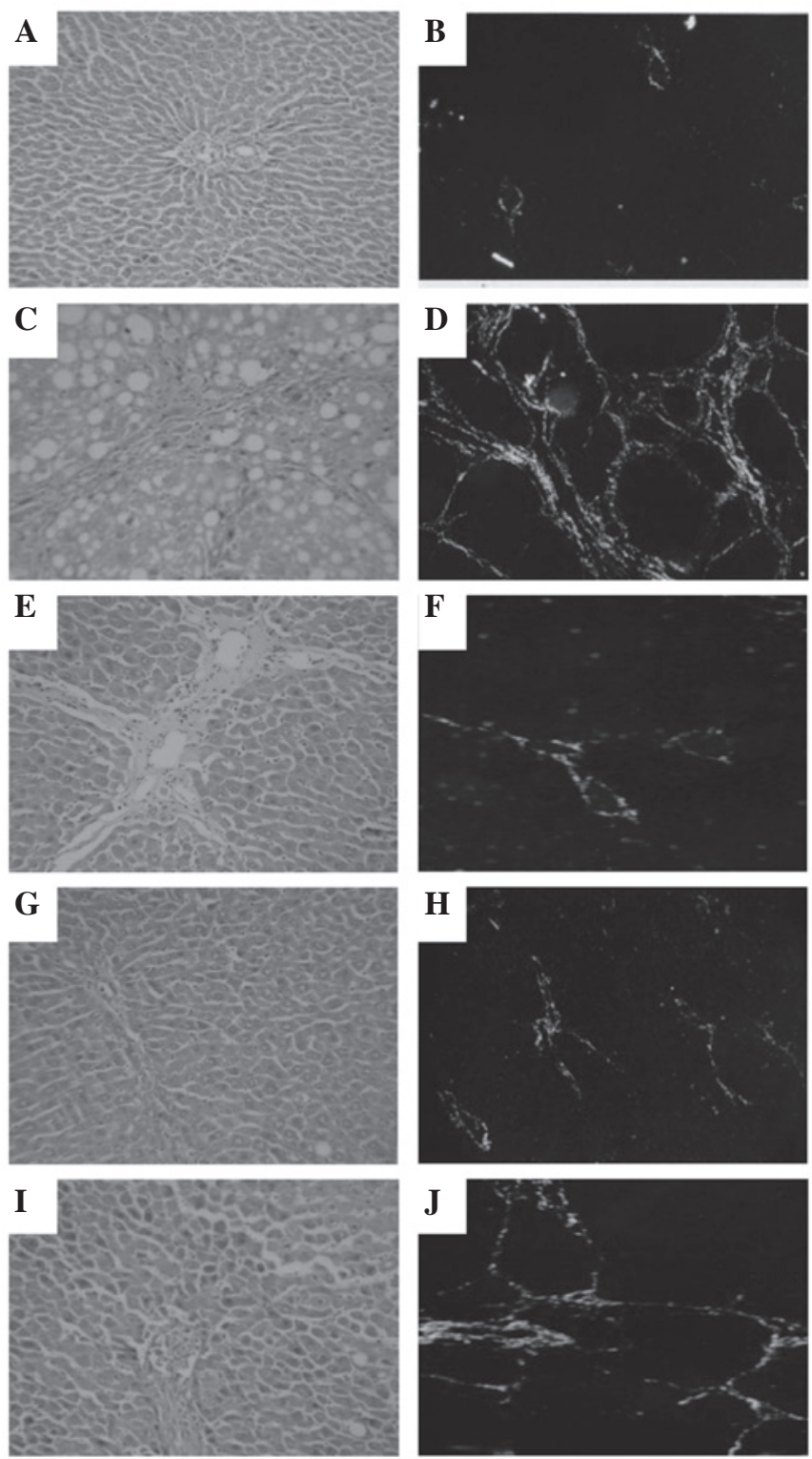

Figure 2. Photomicrographs of rat liver tissues. (A,C,E,G and I) Sections were stained with $H \& E$ (magnification, $x 400)$. (B,D,F,H and J) Sections were stained by picrosirius red and observed under polarizing microscope to assess the presence of collagen. Collagen I was red and III was green (magnification, x200). (A and B) Control, no histological abnormalities; (C and D) $\mathrm{CCl}_{4}$ model, fatty degeneration, necrosis, infiltration of inflammatory cells, formation of fibrotic septa and increased collagen deposition (E,F,G and H) GFK (3,125 and $312.5 \mathrm{mg} / \mathrm{kg} / \mathrm{day})$, the degree of liver damage and fibrosis was markedly reduced and revealed less collagen deposition, particularly collagen type I; (I and J) GFK $(31.25 \mathrm{mg} / \mathrm{kg} / \mathrm{day})$, less statosis and inflammatory cells compared with the model group. HE, hematoxylin-eosin GFK, Gan-fu-kang.

with GFK at $312.5 \mathrm{mg} / \mathrm{kg} /$ day was more effective than treatment with GFK at 3,125 and $31.25 \mathrm{mg} / \mathrm{kg} / \mathrm{day}$ (Fig. 4A). Western blot analysis revealed a significant increase in $\alpha$-SMA, TIMP-1 and collagen I levels in the model group. These effects were markedly reduced by GFK. Response to GFK at $312.5 \mathrm{mg} / \mathrm{kg} /$ day was markedly higher compared with GFK at 3,125 and $31.25 \mathrm{mg} / \mathrm{kg} /$ day (Fig. 4B).

Effect of GFK on expression of genes involved in the Wnt/ $\beta$-catenin signaling pathway. RT-PCR analysis was used
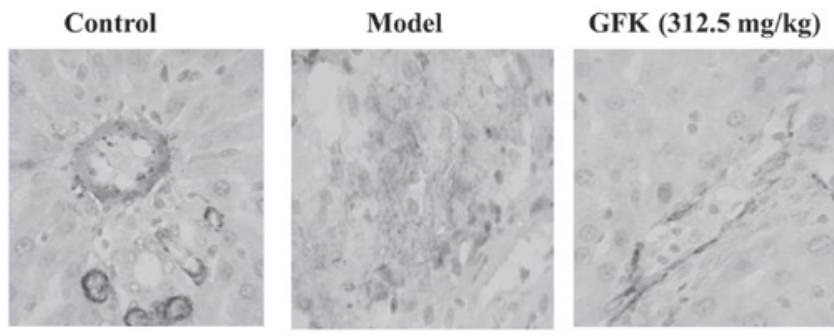

Figure 3. Immunohistochemistry against $\alpha$-SMA in rat liver tissues. Representative micrographs demonstrate $\alpha$-SMA protein localization in different groups as indicated (magnification, x400). $\alpha$-SMA, $\alpha$-smooth muscle actin.

to assess the expression of canonical Wnt genes (Wnt1, Wnt3a and Wnt10b), receptors (Fzd1 and 2), downstream target $(\mathrm{GSK} 3 \beta)$, substrate $(\beta$-catenin) and transcriptional regulator (Tcf-4) in the different groups. In the $\mathrm{CCl}_{4}$ treatment group, with the exception of GSK3 $\beta$, mRNA levels of Wnt1, Wnt3a, Wnt10b, Fzd1, Fzd 2 and $\beta$-catenin were higher, while in the GFK groups, expression was lower (Fig. 5A).

Activation of canonical Wnt signaling results in constitutive stabilization of the free pool of $\beta$-catenin, which travels to the nucleus and binds to Tcf/LEF. The complex modulates transcription of target genes. Therefore, levels of total $\beta$-catenin and nuclear accumulation of $\beta$-catenin in extracts of liver tissue were examined. Western blot analysis revealed increased accumulation of total $\beta$-catenin protein and translocation of $\beta$-catenin into the cell nucleus in the $\mathrm{CCl}_{4}$-treated group (Fig. 5B). Downregulation of $\beta$-catenin in the nucleus and whole cell lysates was observed following treatment with GFK (Fig. 5B).

In the model group, immunohistochemistry revealed enhanced $\beta$-catenin expression in the cytoplasm and clear nuclear staining was observed in single cells. $\beta$-catenin expression was attenuated by GFK prevention treatment (Fig. 5C). A significant increase in positive staining of Tcf- 4 cells was observed in rats following $\mathrm{CCl}_{4}$ treatment. These changes were attenuated following administration of GFK (Fig. 5C).

Effect of GFK on Wnt/ $\beta$-catenin target gene expression. mRNA levels of the putative target gene, cyclin D1, were significantly elevated in rats with liver fibrosis and were reduced by GFK treatment. By contrast, expression of PPAR- $\gamma$ mRNA had an adverse result. The effects induced by GFK $(312.5 \mathrm{mg} / \mathrm{kg} / \mathrm{day})$ were significantly increased when compared with GFK-treated animals (3,125 and $31.25 \mathrm{mg} / \mathrm{kg} /$ day; Fig. 6).

Correlation analysis among Wnt3a, Wnt10b, $\beta$-catenin, Tcf-4, $\alpha$-SMA, TIMP-1, collagen I and collagen III levels. Correlation analysis demonstrated that Wnt3a, Wnt10b, $\beta$-catenin and Tcf-4 significantly correlated with the following measures: $\alpha$-SMA, TIMP-1, collagen I and collagen III $(\mathrm{P}<0.05$ or $\mathrm{P}<0.01$; Table IV).

\section{Discussion}

Chronic injuries to the liver lead to liver fibrosis and subsequent cirrhosis and even hepatocellular carcinoma, and are associated with elevated mortality rates worldwide (29-31). 
A

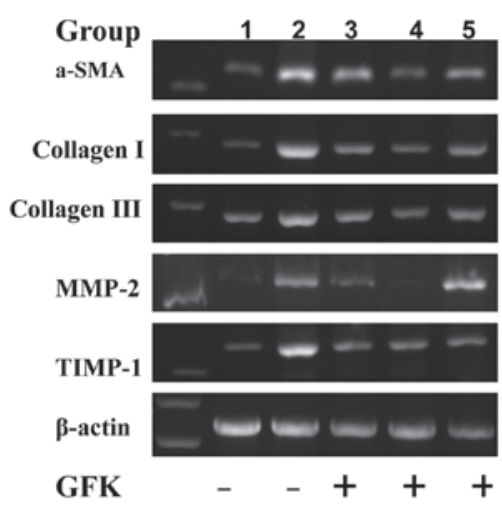

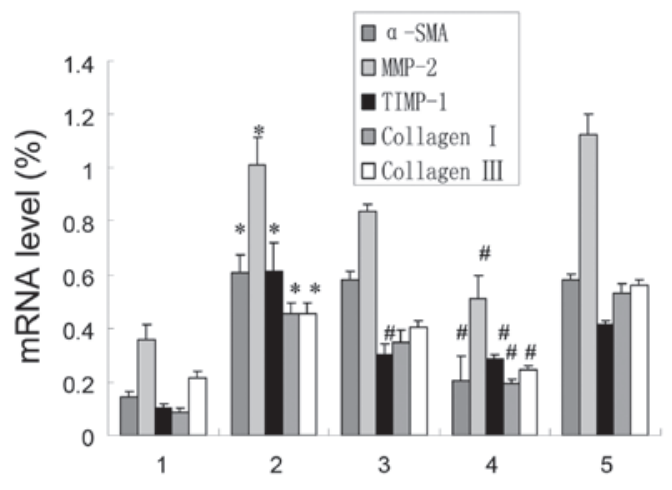

B
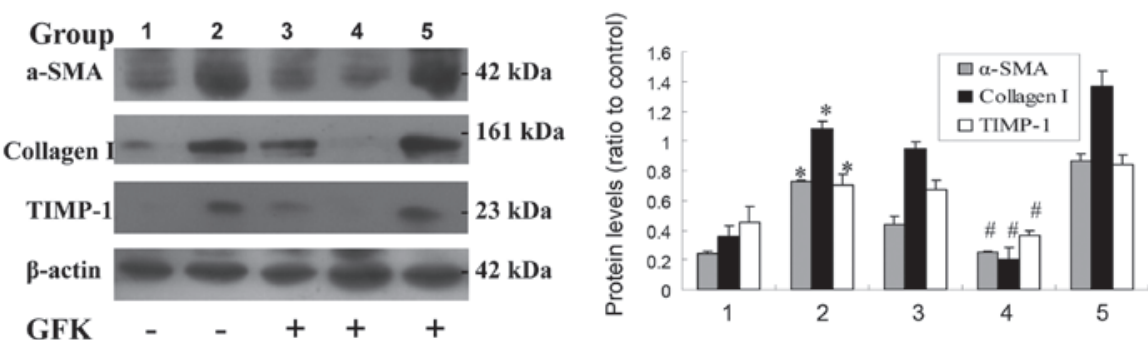

Figure 4. Effect of GFK on the expression of $\alpha$-SMA, collagen I, collagen III, MMP-2 and TIMP-1 in liver fibrosis. (A) Representative RT-PCR analysis and quantification demonstrate that GFKa treatment suppressed the expression of $\alpha$-SMA, collagen I, collagen III, MMP-2 and TIMP-1 mRNA in liver fibrosis induced by $\mathrm{CCl}_{4}$. (B) Representative western blot analysis and quantitative data indicate that treatment with GFK suppressed the expression of $\alpha$-SMA, TIMP-1 and collagen protein I in liver fibrosis induced by $\mathrm{CCl}_{4}$. Lane 1, control; 2, model; 3, GFK (3,125 mg/kg); 4, GFK (312.5 mg/kg); and 5, GFK (31.25 mg/kg). ${ }^{*} \mathrm{P}<0.01$, vs control; ${ }^{\text {"P}} \mathrm{P}<0.01$, vs model. $\alpha$-SMA, $\alpha$-smooth muscle actin; MMP-2, matrix metalloproteinase-2; TIMP-1, tissue inhibitor of metalloproteinase-1; RT-PCR, reverse transcription-polymerase chain reaction; GFK, Gan-fu-kang.

Liver fibrosis is a dynamic process involving increased deposition of ECM components, particularly collagens $(32,33)$. Since there is not an effective treatment approach for irreversible cirrhosis, new potent agents for the treatment of liver fibrosis are required. Medicinally, traditional Chinese herbs have made a significant contribution to the treatment of liver fibrosis (34). The present study revealed that GFK, a traditional Chinese medicine formula, induces a protective effect against $\mathrm{CCl}_{4}$-induced liver fibrosis in rats.

Activities of serum ALT and AST are conventionally used as biochemical makers to assess liver injury $(35,36)$ and in the present study, $\mathrm{CCl}_{4}$ injection resulted in a significant elevation of serum ALT and AST. Administration of GFK (312.5 and 3,125 mg/kg/day) markedly attenuated the increased activities of serum ALT and AST, which indicated that GFK has potent hepatoprotective effects. HA, LN, PCIII and CIV, which are used as indices for the extent of liver fibrosis, were also investigated (37). Observations revealed a significant reduction in these biomarker levels following treatment with GFK. Therefore, we hypothesized that GFK exerts a therapeutic effect on liver fibrotic rats induced by $\mathrm{CCl}_{4}$, and the repressive effect of GFK at $312.5 \mathrm{mg} / \mathrm{kg} /$ day is superior to that of GFK at 3,125 and $31.25 \mathrm{mg} / \mathrm{kg} /$ day.

Activation and proliferation of HSCs plays a pivotal role in liver fibrogenesis. When activated, HSCs undergo phenotypic transformation between a quiescent cell and myofibrolast-like cell and drive fibrogenesis by synthesizing and releasing $\alpha$-SMA filaments and ECM, including type I and III collagens $(38,39)$. $\alpha$-SMA, a characteristic cytoskeletal protein, is considered a marker of activated HSCs. Collagens are the main components of the ECM, primarily composed of collagen I and III, which account for $95 \%$ of the total collagen in fibrotic liver. The present study revealed an antifibrogenesis effect caused by GFK decreasing the expression of $\alpha$-SMA, collagen I and III in $\mathrm{CCl}_{4}$-treated animals. This observation was further supported by histological observations. Results of $\alpha$-SMA immunostaining confirmed that the activity of HSCs in GFK therapeutic rats was markedly less than in $\mathrm{CCl}_{4}$-treated rats.

The outcome of fibrogenesis is the accumulation and degradation of ECM, which is regulated by a family of zinc-dependent enzymes, MMPs, and their inhibitors, TIMPs (40). MMP-2 is produced by activated HSCs and is considered to be important for remodeling of the basement membrane during tissue repair (41). TIMP-1 is an inhibiting factor of MMPs and previous studies have revealed that TIMP-1 not only inhibits collagenase activity, but also inhibits MMPs and stromelysin activity $(42,43)$. The present study revealed that rats receiving $\mathrm{CCl}_{4}$ exhibited elevated MMP-2 and TIMP-1 expression, while this effect was abrogated by GFK treatment. These results indicate that GFK may regulate the balance between MMPs and TIMPs.

Wnt signaling via $\beta$-catenin is implicated in embryonic development and tissue homeostasis (22). Consequently, mutations in the Wnt signaling pathway are often associated with a number of genetic defects, cancer and other diseases (44). Previous studies have demonstrated that the activation of the Wnt pathway results in fibrogenic 
A
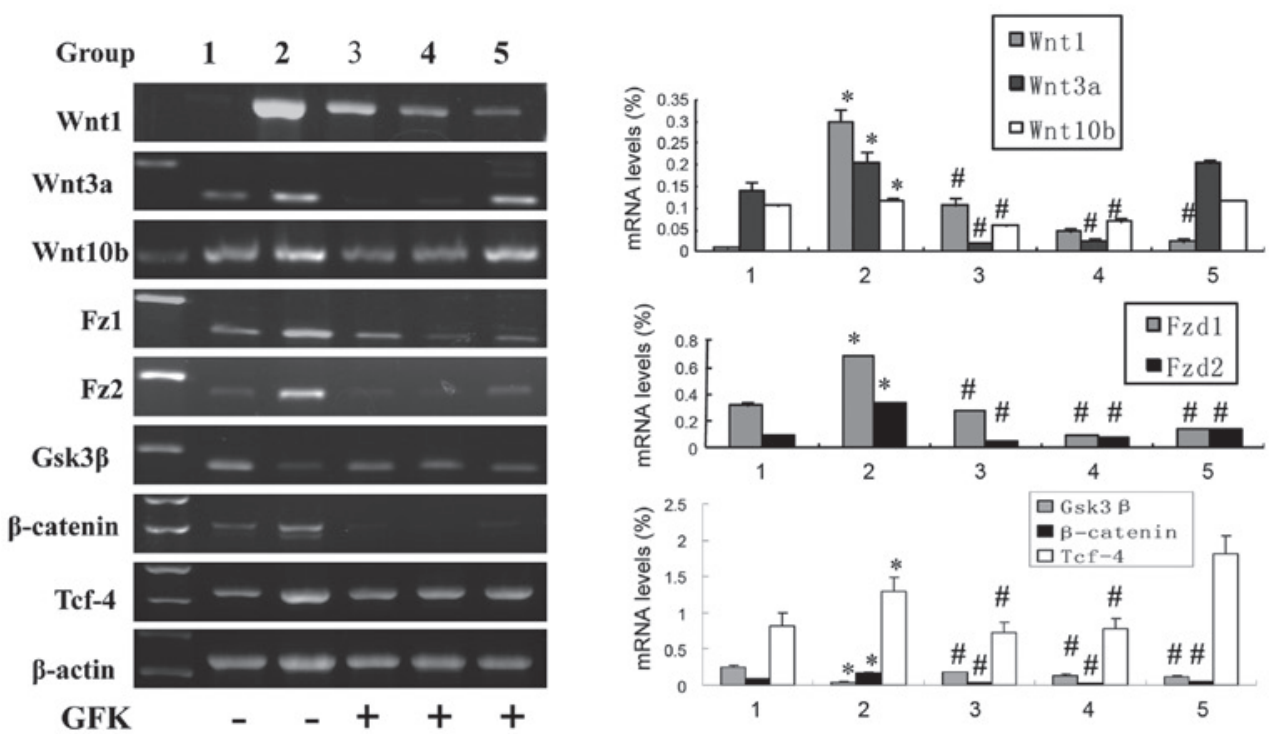

B
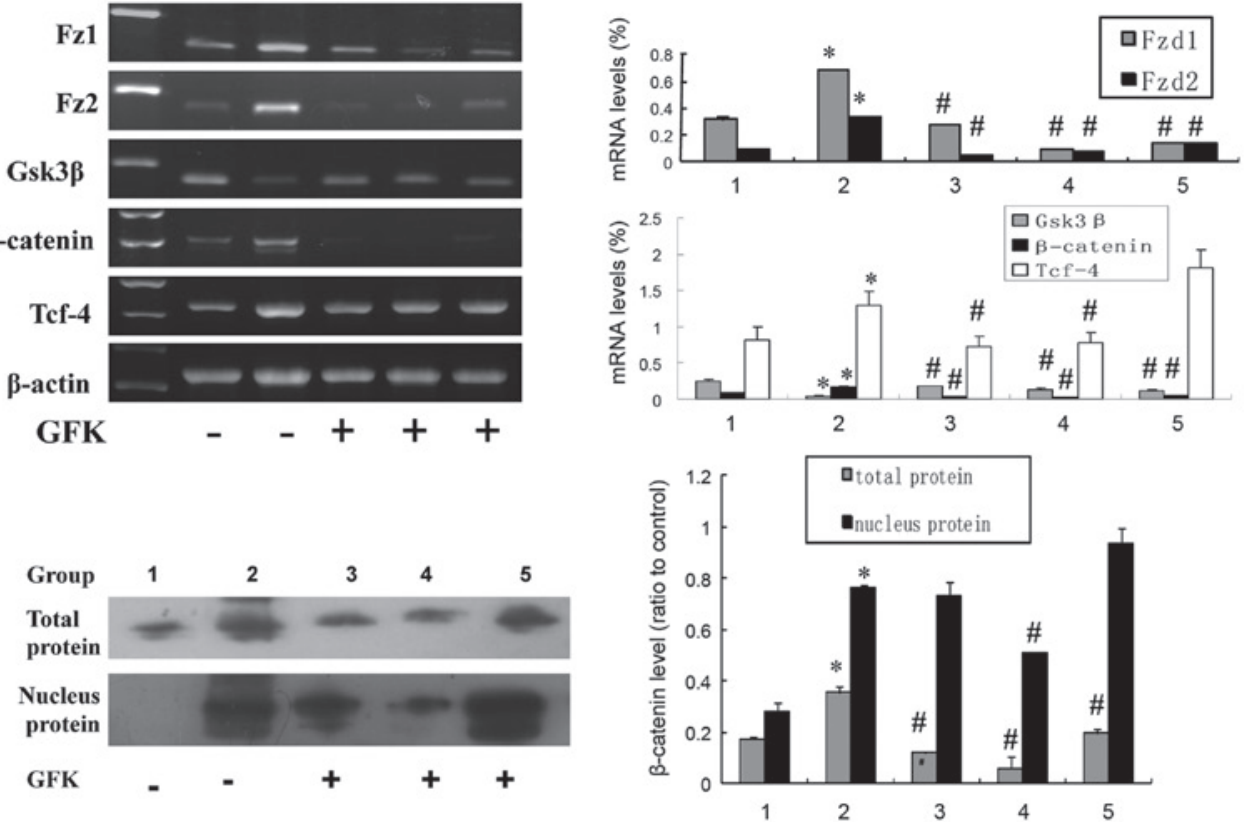

C

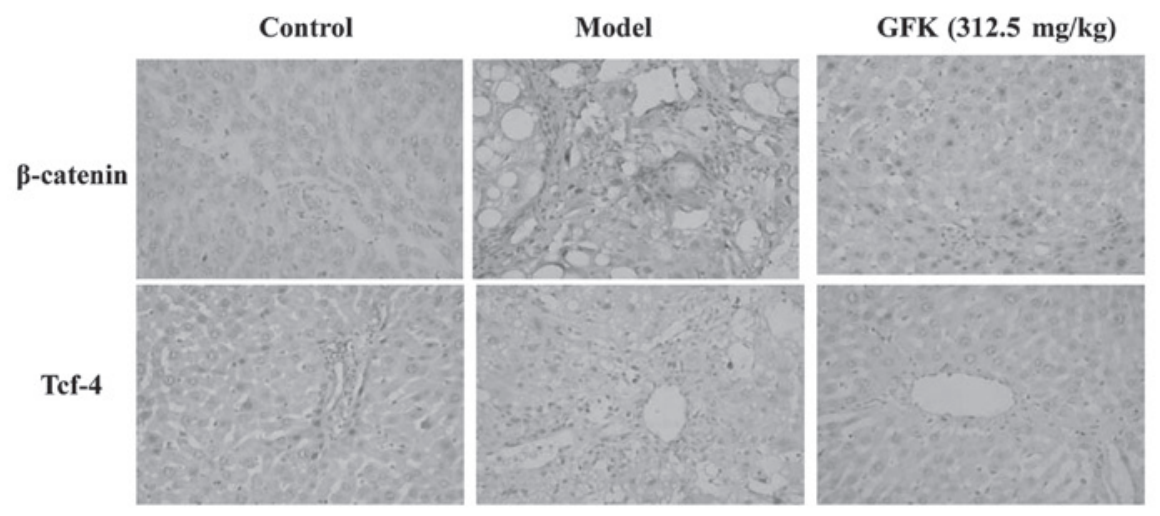

Figure 5. Effect of GFK on Wnt/ $\beta$-catenin signaling pathway genes. (A) Effect of GFK on the mRNA expression of genes in the Wnt/ $\beta$-catenin signaling pathway. Left, expression of associated genes in the Wnt/ $\beta$-catenin signaling pathway and right, densitometric analysis of the results. (B) Effect of GFK on nuclear translocation of $\beta$-catenin in rat livers. GFK treatment interferes with the localization of $\beta$-catenin protein. Densitometric analysis of each band. (C) Immunohistochemistry against $\beta$-catenin and Tcf-4 proteins in rat liver sections (magnification, $\mathrm{x} 400$ ). Brown indicates specific Ab reactivity. In the CCl4 group, $\beta$-catenin and Tcf- 4 were markedly upregulated revealing positive staining at the fibrotic septa and downregulated in the GFK (312.5 mg/ $\mathrm{kg})$ group. Lane 1, control; 2, model; 3, GFK (3,125 mg/kg); 4, GFK (312.5 mg/kg); and 5, GFK (31.25 mg/kg). " $\mathrm{P}<0.01$, vs. control; " $\mathrm{P}<0.05$, vs. model. GFK, Gan-fu-kang; CCl4,carbon tetrachloride 4.
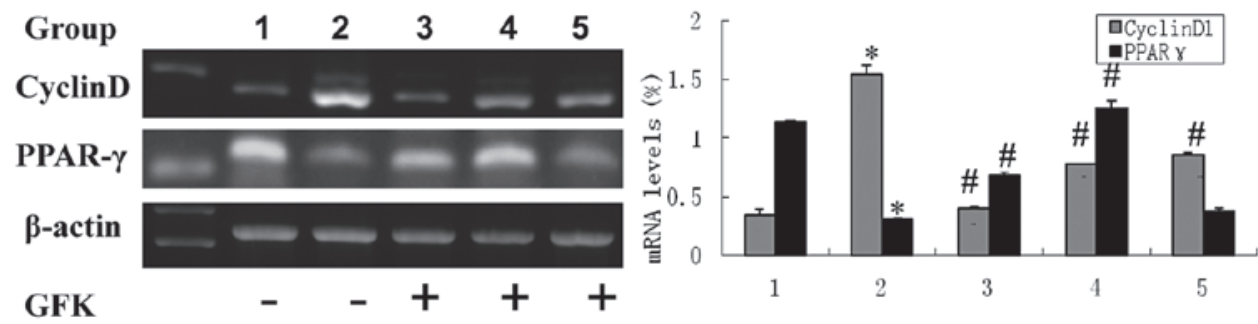

Figure 6. Effect of GFK on the expression of cyclinD1 and PPAR- $\gamma$ on CCl4-injured liver fibrosis. RT-PCR analysis and quantification indicate induction of cyclin D1 in the fibrotic liver and reveals that GFK administration significantly decreased expression of cyclin D1; PPAR- $\gamma$ mRNA had an adverse result. Lane 1, control; 2, model; 3, GFK (3,125 mg/kg); 4, GFK (312.5 mg/kg); and 5, GFK (31.25 mg/kg). "P<0.01, vs. control; ${ }^{*} \mathrm{P}<0.01$, vs. model. GFK, Gan-fu-kang; RT-PCR, reverse transcription-polymerase chain reaction; $\mathrm{CCl} 4$,carbon tetrachloride 4. 
conversion of numerous tissues, including lung, kidney and muscle (45-49). Previously, HSCs were reported to exhibit upregulation of the Wnt signaling pathway in vitro and several inhibitors were found to antagonize or modulate this pathway in these cells $(50,51)$. In addition, the Wnt/ $\beta$-catenin pathway has been reported to maintain the inactivity stage of HSCs (52). The present study was designed to determine whether the Wnt/ $\beta$-catenin signaling pathway is involved in fibrosis and to investigate the antifibrotic effect of GFK in vivo using $\mathrm{CCl}_{4}$-induced liver fibrosis in $\mathrm{SD}$ rats. The observations revealed that expression of Wnt and their corresponding Fzd receptor genes increased in the fibrotic liver, indicating that the response of canonical Wnt proteins and receptors is consistent with the damage of $\mathrm{CCl}_{4}$. In the present study, it was demonstrated that expression of GSK $3 \beta$ was downregulated and its effector, $\beta$-catenin, was upregulated. These changes indicated that the Wnt signaling was in an active state. In agreement, mRNA and protein levels increased and were mainly distributed in the cell plasma and nuclei, revealing that the $\mathrm{Wnt} / \beta$-catenin pathway was activated. Following this, Tcf- 4 was found to be a key partner for $\beta$-catenin at the protein level via western blot analysis and immunohistochemistry. This observation revealed a correlation between upregulation and increasing mRNA levels, localized predominantly at the nuclei of hepatic cells. These observations are consistent with a previous study in which the formation of $\beta$-catenin/Tcf- 4 complex was reported to be essential for the Wnt signaling cascade (53). The changes were reversed following GFK treatment.

The ultimate effect of the Wnt/ $\beta$-catenin pathway is the regulation of downstream target genes. Therefore, two putative target genes, cyclin D1 and PPAR $-\gamma$, in fibrotic liver were investigated. Cyclin D1 is a pivotal member of the cyclin family and is widely considered to control cell proliferation and differentiation via induction of cell entry into the $\mathrm{S}$-phase and $\mathrm{G}_{2}$ /M-phase (54). Overexpression of cyclin D1 is involved in HSC proliferation in rat liver (55). The upregulation of cyclinD1 in fibrotic liver and its downregulation following treatment with GFK was observed, indicating that its activation may be essential for the evolution of liver fibrosis. The Wnt/ $\beta$-catenin pathway is known to expand in liver fibrosis, mainly due to an additional target, PPAR $-\gamma$. PPAR $-\gamma$ is a member of the nuclear receptor family and is capable of stimulating adipocyte differentiation, regulating lipid metabolism, activating insulin, inhibiting cell proliferation and inducing apoptosis (56). A previous study revealed that treatment with PPAR- $\gamma$ ligands blocks liver fibrosis in animal models (57). The present study demonstrated that the Wnt/ $\beta$-catenin signaling may suppress PPAR- $\gamma$ activity and GFK treatment may upregulate the amplification of PPAR- $\gamma$. This is consistent with the observation that PPAR $-\gamma$ may conversely inhibit Wnt/ $\beta$-catenin signaling by promoting the degradation of $\beta$-catenin $(58,59)$. A number of other transcription factors may be involved in the modulation of Wnt target genes, thus this area requires further investigation.

Correlation analysis revealed that the expression of $\alpha$-SMA, TIMP-1, collagen I and collagen III closely correlate with the abundance of the associated factors, Wnt3a, Wnt10b, $\beta$-catenin and Tcf- 4 , in the Wnt/ $\beta$-catenin signaling pathway.
In summary, the present study indicates that the herbal medicine GFK prevents $\mathrm{CCl}_{4}$-induced rat liver fibrosis and that this action may be caused, in part, by its depressing effect on the canonical Wnt/ $\beta$-catenin pathway. Therefore, GFK represents a potential therapeutic strategy for improving liver fibrosis. Further investigation is required to specify how/which components of GFK exert antifibrotic functions and its exact role in various liver cell types.

\section{Acknowledgements}

The authors thank Dr Joel Tatenda Mafemba for valuable proofreading of the manuscript. This study was financially supported by the Natural Science Foundation of Liaoning Province, China (201102055).

\section{References}

1. Friedman SL: Molecular regulation of hepatic fibrosis, an integrated cellular response to tissue injury. J Biol Chem 275: 2247-2250, 2000

2. Cheng M and Yang C (eds): The Basic Study and Clinical Research on Hepatic Fibrosis. First edition. First Jumbo Publishing Co., California, USA, 2002.

3. Moreira RK: Hepatic stellate cells and liver fibrosis. Arch Pathol Lab Med 131: 1728-1734, 2007.

4. Wu J and Zern MA: Hepatic stellate cells: a target for the treatment of liver fibrosis. J Gastroenterol 35: 665-672, 2000.

5. Mann J and Mann DA: Transcriptional regulation of hepatic stellate cells. Adv Drug Deliv Rev 61: 497-512, 2009.

6. Gäbele E, Brenner DA and Rippe RA: Liver fibrosis: signals leading to the amplification of the fibrogenic hepatic stellate cell. Front Biosci 8: d69-d77, 2003.

7. Zou YH, Yang Y, Li J, et al: Potential therapeutic effects of a traditional Chinese formulation, BJ-JN, on liver fibrosis induced by carbon tetrachloride in rats. J Ethnopharmacol 120: 452-457, 2008.

8. Purps O, Lahme B, Gressner AM, Meindl-Beinker NM and Dooley S: Loss of TGF-beta dependent growth control during HSC transdifferentiation. Biochem Biophys Res Commun 353: 841-847, 2007

9. Borkham-Kamphorst E, van Roeyen CR, Ostendorf T, Floege J, Gressner AM and Weiskirchen R: Pro-fibrogenic potential of PDGF-D in liver fibrosis. J Hepatol 46: 1064-1074, 2007.

10. Brewster UC, Setaro JF and Perazella MA: The renin-angiotensin-aldosterone system: cardiorenal effects and implications for renal and cardiovascular disease states. Am J Med Sci 326: 15-24, 2003.

11. Cadigan KM and Nusse R: Wnt signaling: a common theme in animal development. Genes Dev 11: 3286-3305, 1997.

12. Lin X, Zhang S, Huang Q, et al: Protective effect of Fufang-LiuYue-Qing, a traditional Chinese herbal formula, on CCl4 induced liver fibrosis in rats. J Ethnopharmacol 142: 548-556, 2012.

13. Xu TT, Jiang MN, Li C, Che Y and Jia YJ: Effect of Chinese traditional compound, Gan-fu-kang, on $\mathrm{CCl}(4)$-induced liver fibrosis in rats and its probable molecular mechanisms. Hepatol Res 37: 221-229, 2007

14. Gao Y, Song LX, Jiang MN, Ge GY and Jia YJ: Effects of traditional chinese medicine on endotoxin and its receptors in rats with non-alcoholic steatohepatitis. Inflammation 31: 121-132, 2008

15. Lee PN, Pang K, Matus DQ and Martindale MQ: A WNT of things to come: evolution of Wnt signaling and polarity in cnidarians. Semin Cell Dev Biol 17: 157-167, 2006.

16. Zhao J, Kim KA and Abo A: Tipping the balance: modulating the Wnt pathway for tissue repair. Trends Biotechnol 27: 131-136, 2009.

17. Lustig B and Behrens $\mathrm{J}$ : The Wnt signaling pathway and its role in tumor development. J Cancer Res Clin Oncol 129: 199-221, 2003.

18. Kikuchi A and Yamamoto H: Tumor formation due to abnormalities in the $\beta$-catenin-independent pathway of Wnt signaling. Cancer Sci 99: 202-208, 2008.

19. Zhang B, Zhou KK and Ma JX: Inhibition of connective tissue growth factor overexpression in diabetic retinopathy by SERPINA3K via blocking the WNT/beta-catenin pathway. Diabetes 59: 1809-1816, 2010. 
20. Morrisey EE: Wnt signaling and pulmonary fibrosis. Am J Pathol 162: 1393-1397, 2003.

21. Habas R and Dawid IB: Dishevelled and Wnt signaling: is the nucleus the final frontier? J Biol 4: 2, 2005.

22. Logan CY and Nusse R: The Wnt signaling pathway in development and disease. Annu Rev Cell Dev Biol 20: 781-810, 2004

23. Ross SE, Hemati N, Longo KA, Bennett CN, Lucas PC, Erickson RL and MacDougald OA: Inhibition of adipogenesis by Wnt signaling. Science 289: 950-953, 2000.

24. Cheng JH, She H, Han YP, et al: Wnt antagonism inhibits hepatic stellate cell activation and liver fibrosis. Am J Physiol Gastrointest Liver Physiol 294: G39-G49, 2008.

25. Lou JL, Jiang MN, Li C, et al: Herb medicine Gan-fu-kang attenuates liver injury in a rat fibrotic model. J Ethnopharmacol 128: 131-138, 2010.

26. National Institutes of Health: Guide for the Care and Use of Laboratory Animals. Sixth edition. National Acadamies Press, Washington, D.C., 1985.

27. Nie QH, Cheng YQ, Xie YM, Zhou YX and Cao YZ: Inhibiting effect of antisense oligonucleotides phosphorthioate on gene expression of TIMP-1 in rat liver fibrosis. World J Gastroenterol 7: 363-369, 2001.

28. Dignani JD, Lebovitz RM and Roeder RG: Accurate transcription initiation by RNA polymerase II in a soluble extract from isolated mammalian nuclei. Nucleic Acids Res 11: 1475-1489, 1983.

29. Castera L: Assessing liver fibrosis. Expert Rev Gastroenterol Hepatol 2: 541-552, 2008

30. Faria SC, Ganesan K, Mwangi I, et al: MR imaging of liver fibrosis: current state of the art. Radiographics 29: 1615-1635, 2009.

31. Watson MR, Wallace K, Gieling RG, et al: NF-kappaB is a critical regulator of the survival of rodent and human hepatic myofibroblasts. J Hepatol 48: 589-597, 2008.

32. Tsukada S, Parsons CJ and Rippe RA: Mechanisms of liver fibrosis. Clin Chim Acta 364: 33-60, 2006.

33. Friedman SL: Liver fibrosis-from bench to bedside. J Hepatol 38 : S38-S53, 2003

34. Fowell AJ and Iredale JP: Emerging therapies for liver fibrosis Dig Dis 24: 174-183, 2006.

35. Sturgill MG and Lambert GH: Xenobiotic-induced hepatotoxicity: mechanisms of liver injury and methods of monitoring hepatic function. Clin Chem 43: 1512-1526, 1997.

36. Achliya GS, Wadodkar SG and Dorle AK: Evaluation of hepatoprotective effect of Amalkadi Ghrita against carbon tetrachloride-induced hepatic damage in rats. J Ethnopharmacol 90: 229-232, 2004

37. Leroy V: Other non-invasive markers of liver fibrosis Gastroenterol Clin Biol 32 (6 Suppl 1): 52-57, 2008.

38. Bataller R and Brenner DA: Liver fibrosis. J Clin Invest 115 209-218, 2005

39. Lotersztajn S, Julien B, Teixeira-Clerc F, Grenard P and Mallat A Hepatic fibrosis: molecular mechanisms and drug targets. Annu Rev Pharmacol Toxicol 45: 605-628, 2005.

40. Li D and Friedman SL: Liver fibrogenesis and the role of hepatic stellate cells: new insights and prospects for therapy. J Gastroenterol Hepatol 14: 618-633, 1999.

41. Han YP: Matrix metalloproteinases, the pros and cons, in liver fibrosis. J Gastroenterol Hepatol 21 (Suppl 3): S88-S91, 2006.
42. Lichtinghagen R, Michels D, Haberkorn CI, et al: Matrix metalloproteinase (MMP)-2, MMP-7 and tissue inhibitor of metalloproteinase-1 are closely related to the fibroproliferative process in the liver during chronic hepatitis C. J Hepatol 34: 239-247, 2001.

43. Arthur MJ, Mann DA and Iredale JP: Tissue inhibitors of metalloproteinases, hepatic stellate cells and liver fibrosis. J Gastroenterol Hepatol 13: S33-S38, 1998.

44. Clevers H: Wnt/beta-catenin signaling in development and disease. Cell 127: 469-480, 2006.

45. Chilosi M, Poletti V, Zamò A, et al: Aberrant Wnt/beta-catenin pathway activation in idiopathic pulmonary fibrosis. Am J Pathol 162: 1495-1502, 2003

46. Königshoff M, Balsara N, Pfaff EM, et al: Functional Wnt signaling is increased in idiopathic pulmonary fibrosis. PLoS One 3: e2142, 2008

47. Luk JM, Wang X, Liu P, et al: Traditional Chinese herbal medicines for treatment of liver fibrosis and cancer: from laboratory discovery to clinical evaluation. Liver Int 27: 879-890, 2007.

48. He W, Dai C, Li Y,Zeng G, Monga SP and Liu Y: Wnt/beta-catenin signaling promotes renal interstitial fibrosis. J Am Soc Nephrol 20: 765-776, 2009.

49. Brack AS, Conboy MJ, Roy S, et al: Increased Wnt signaling during aging alters muscle stem cell fate and increases fibrosis. Science 317: 807-810, 2007

50. Jiang F, Parsons CJ and Stefanovic B: Gene expression profile of quiescent and activated rat hepatic stellate cells implicates Wnt signaling pathway in activation. J Hepatol 45: 401-409, 2006.

51. Myung SJ, Yoon JH, Gwak GY, et al: Wnt signaling enhances the activation and survival of human hepatic stellate cells. FEBS Lett 581: 2954-2958, 2007.

52. Kordes C, Sawitza I and Häussinger D: Canonical Wnt signaling maintains the quiescent stage of hepatic stellate cells. Biochem Biophys Res Commun 367: 116-123, 2008.

53. MacDonald BT, Tamai K and He X: Wnt/beta-catenin signaling: components, mechanisms and diseases. Dev Cell 17: 9-26, 2009.

54. Ying J, Li H, Yu J, et al: WNT5A exhibits tumor-suppressive activity through antagonizing the Wnt/beta-catenin signaling, and is frequently methylated in colorectal cancer. Clin Cancer Res 14: 55-61, 2008.

55. Albrecht JH and Hansen LK: Cyclin D1 promotes mitogen-independent cell cycle progression in hepatocytes. Cell Growth Differ 10: 397-404, 1999

56. Houseknecht KL, Cole BM and Steele PJ: Peroxisome proliferator-activated receptor gamma (PPARgamma) and its ligands: a review. Domest Anim Endocrinol 22: 1-23, 2002.

57. Galli A, Crabb DW, Ceni E, et al: Antidiabetic thiazolidinediones inhibit collagen synthesis and hepatic stellate cell activation in vivo and in vitro. Gastroenterology 122: 1924-1940, 2002.

58. Liu J and Farmer SR: Regulating the balance between peroxisome proliferator-activated receptor gamma and beta-catenin signaling during adipogenesis. A glycogen synthase kinase 3 beta phosphorylation-defective mutant of beta-catenin inhibits expression of a subset of adipogenic genes. J Biol Chem 279: 45020-45027, 2004.

59. Moldes M, Zuo Y, Morrison RF, et al: Peroxisome-proliferatoractivated receptor gamma suppresses Wnt/betacatenin signalling during adipogenesis. Biochem J 376: 607-613, 2003. 